\title{
Er:YAG and adhesion in conservative dentistry : clinical overview
}

\author{
Carlo Fornaini MD, DDS, IMeLaS 1,2 \\ 1: Dental School, Faculty of Medicine and Surgery, University of Parma, Italy \\ 2: Faculty of Dentistry, University of Nice-Sophia Antipolis, France
}

\begin{abstract}
The notion of utilizing laser technology in conservative dentistry was proposed in 1990 by Hibst and Keller, who introduced the possibility of using an Er:YAG laser as alternative to conventional instruments such as the turbine and micro-motor. In subsequent years a continuing effort has been made by clinicians, researchers and commercial companies to improve the technology.

The aim of this clinical study is to demonstrate, by the description of different clinical cases, the possibilities and the advantages of using Er:YAG lasers in conservative dentistry and to show that better results may be achieved in terms of stronger adhesion, less invasiveness, reduced pain as well as greater comfort and satisfaction of patients.
\end{abstract}

\section{Introduction}

The field of adhesive dentistry was introduced in 1955 by Buonocore, with the description of the utilisation of orthophosphoric acid and composite resin in order to obtain restorations with high bond strength and reduced microleakage ${ }^{1-2}$ ). In 1990 laser technology was introduced in conservative dentistry by Hibst and Keller, who described the possibility to use an Er:YAG laser as alternative to conventional instruments, such as the turbine and micromotor ${ }^{3-4)}$. Widespread interest in employing this new technology stems from a number of significant advantages, as described in several scientific studies. Thanks to the affinity of the Er:YAG laser wavelength $(2940 \mathrm{~nm})$ to water (absorption peak = $3000 \mathrm{~nm}$ ) and hydroxyapatite (absorption peak = 2800nm), laser technology allows for efficient ablation of hard dental tissues without the risk of micro- and macro-fractures, as have been observed with the use of conventional rotating instruments $5-6$ ). The dentin surface treated by laser appears clean, without a smearlayer and with the tubules open and clear ${ }^{7)}$.

\footnotetext{
Addressee for Correspondence:

Carlo Fornaini MD, DMD, MSc

Faculty of Dentistry

University of Nice-Sophia Antipolis

Nice, France

E-mail: carlo@fornainident.it
}

Thermal elevation in the pulp, recorded during Er:YAG laser irradiation, is lower than that recorded by using a turbine and micro-motor with the same conditions of air/water spray ${ }^{8-9)}$. This wavelength also has an antimicrobial decontamination effect on the treated tissue, which destroys both aerobic and anaerobic bacteria ${ }^{10)}$. The most interesting aspects of this new technology are related to the goals of modern conservative dentistry: i.e. minimally invasive treatments and adhesive dentistry. Er:YAG lasers can reach spot dimensions smaller than $1 \mathrm{~mm}$, which enables a selective ablation of the affected dentin while preserving the surrounding sound tissue to produce highly efficient restorations ${ }^{11}$ ). Several in vitro studies have demonstrated that the preparation of enamel and dentine by Er:YAG laser, followed by orthophosphoric acid-etching, enhances effectiveness in terms of reduced microleakage and increased bond strength ${ }^{12)}$.

The aim of this clinical study was to describe, by showing several different clinical cases, the characteristics of the use of Er:YAG in the treatment of hard dental tissues, the advantages compared to the utilization of traditional instruments and the fields of dentistry where it is possible to employ it.

Received Date: December 25th, 2012 Accepted Date: February 5th, 2013 


\section{Material and methods}

The most important evolution in conservative dentistry in recent decades is the transition from the use of amalgam fillings to composite resins. This has brought with it a real revolution of the concepts of cavity preparation: from "extension for prevention" 13) and the notion of mechanical retention, where a glaze surface was required, to a minimal volume of ablation and a rough surface in order to obtain an adhesive retention.

For this reason the role of the Er:YAG laser in modern conservative dentistry is of greater and greater importance: it is able to make a very small cavity and, by realizing a rough surface, to increase the adhesion of the composite resin. If this is desirable in the whole of conservative dentistry, it becomes strictly necessary in particular clinical situations where a minimal volume of ablation and/or greater adhesion are required, i.e. pits and fissures sealing, fluorosis or enamel defects, spots 14) and crown fractures of frontal teeth ${ }^{15}$ ).

\section{Case report 1:}

A 9-year-old female in treatment for sealing of her first permanent molars was treated with an Er:YAG laser (LightWalker, Fotona, SLO) and 37\% orthophosphoric acid-etching, without anaesthetic.

Parameters: $90 \mathrm{~mJ}, 10 \mathrm{~Hz}, \mathrm{MSP}$, non-contact handpiece (0.9 mm spot size).

The advantages are decontamination and composite adhesion increase.

(pictures 1-2-3-4)

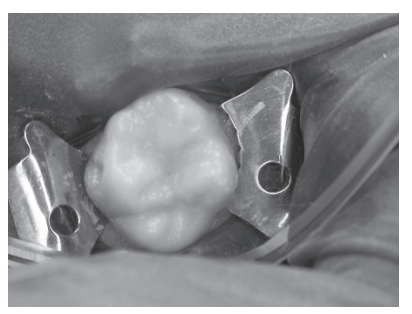

picture 1

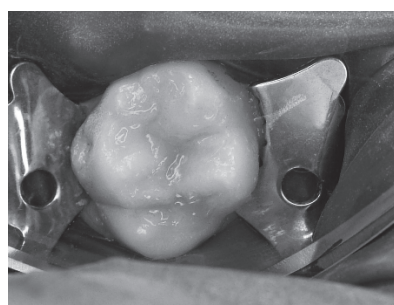

picture 3

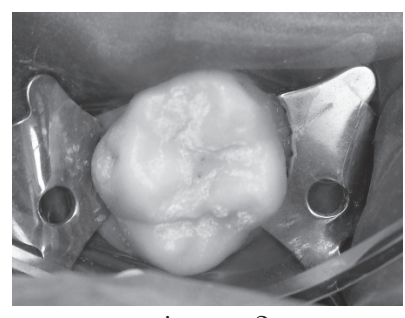

picture 2

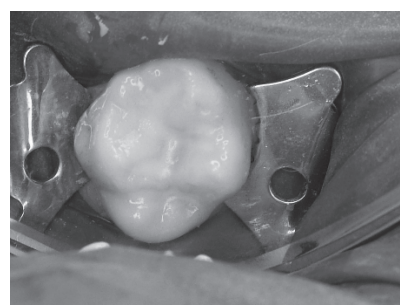

picture 4

\section{Case report 2:}

A 14-year-old female seeking aesthetic restorations of white spots in the permanent incisors, likely caused by fluorosis, was treated with an Er:YAG laser (LightWalker, Fotona, SLO) and 37\% orthophosphoric acid-etching, without anaesthetic.

Parameters: $150 \mathrm{~mJ}, 10 \mathrm{~Hz}$, SSP, non-contact handpiece $(0.9 \mathrm{~mm}$ spot size). The main advantage, beyond the benefits previously described, was enabled by the ability to achieve a minimal volume of ablated tissue.

(pictures 5-6-7-8)

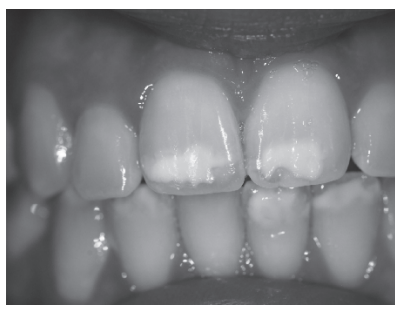

picture 5

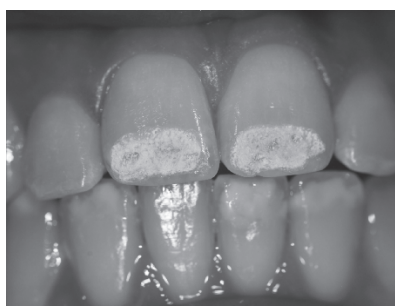

picture 7

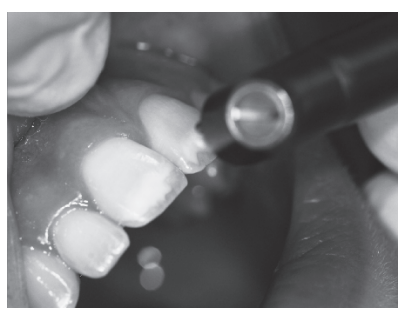

picture 6

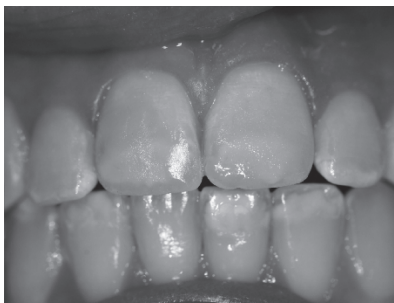

picture 8

\section{Case report 3}

A 16-year-old male in need of an aesthetic restoration for a traumatic crown fracture of the upper permanent central incisors was treated with an Er:YAG laser (LightWalker, Fotona, SLO) and $37 \%$ orthophosphoric acid-etching, without anaesthetic.

Parameters: $200 \mathrm{~mJ}, 10 \mathrm{~Hz}, \mathrm{MSP}$, non-contact handpiece $(0.9 \mathrm{~mm}$ spot). The main advantage in this case was the ability to obtain a strong linkage between the teeth and resin, able to support masticatory forces.

(pictures 9-10-11-12) 


\section{ORIGINAL ARTICLES}

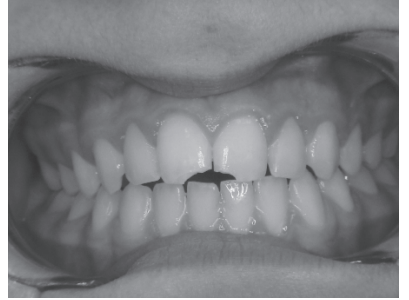

picture 9

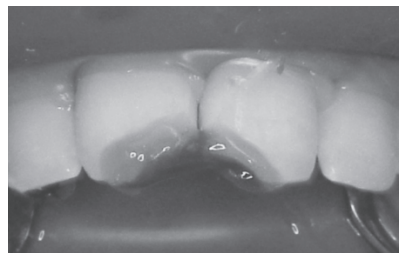

picture 11

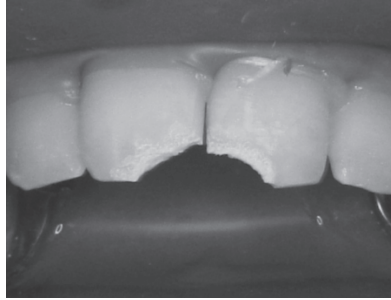

picture 10

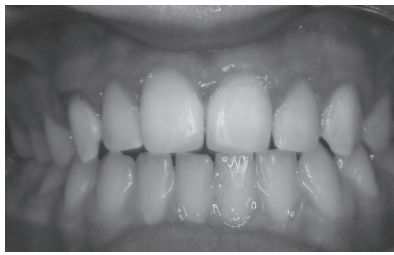

picture 12

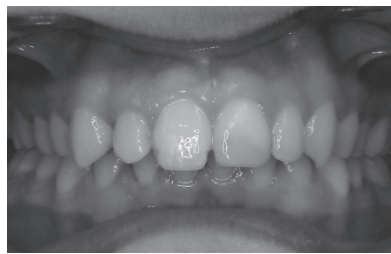

picture 13

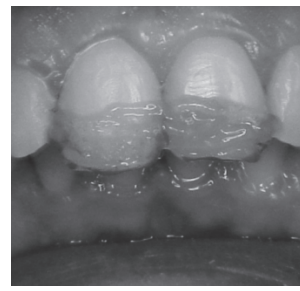

picture 15

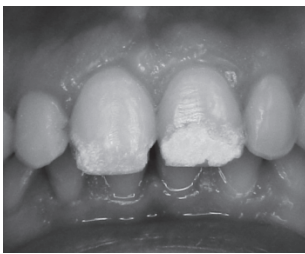

picture 14

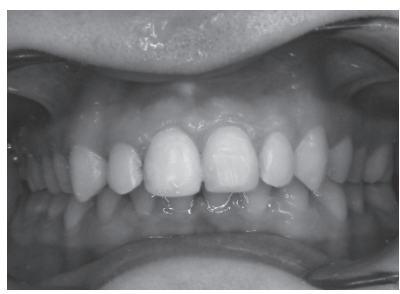

picture 16
While it is not possible to remove aging amalgam restorations by Er:YAG laser due to a number of reasons including the risk of pollution with mercury micro-particles (which may be inhaled by the patient, operator and personal) the removal of aging composite fillings is a very interesting application of this device. In fact, due to its wavelength (2940 $\mathrm{nm}$ ) it is well absorbed by Glycidyl methacrylate (GMA) and Silicon Dioxide, two important components of composite, making it very effective in the ablation of such restorations without thermal elevation 16). Additionally, it can produce a rough surface, very difficult to obtain with orthophosphoric acid, which is able to effectively bond the new coat of resin.

\section{Case report 4}

After orthodontic treatment, a 21-year-old female wished to improve the aesthetic appearance of her upper central incisors, where composite restorations had been made several years before. To remove the superficial coat of resin, an Er:YAG laser (LightWalker, Fotona, SLO) was used and a new coat of composite was applied.

Parameters: $200 \mathrm{~mJ}, 10 \mathrm{~Hz}, \mathrm{MSP}$, non-contact handpiece (0.9 mm spot size).

\section{(pictures 13-14-15-16)}

An advantage of the utilization of Erbium lasers in conservative dentistry, as described by several authors, 1718) stems from the low level of pain produced during the irradiation, allowing for treatments without the use of anaesthetics, even in cases of deep cavities and/or non-carious lesions in the cervical zone. There are

many reasons that may contribute to this effect.: the most important is that pulse durations may be very short, especially as low as $50 \mathrm{sec}$ (using variable square pulse technology from Fotona d.d.) so preventing heat diffusion in the tissue.

\section{Case report 5}

A 42-year-old male was treated for a carious lesion on the occlusal face of the first lower left molar. An Er:YAG laser (LightWalker, Fotona, SLO) was used to remove the infected tissue and, after the preparation, the cavity appeared very deep, also involving a part of the lingual side. The entire intervention was performed without anaesthetic.

Parameters: $250 \mathrm{~mJ}, 10 \mathrm{~Hz}$, SSP, non-contact handpiece (0.9 mm spot).

\section{(pictures 17-18-19)}

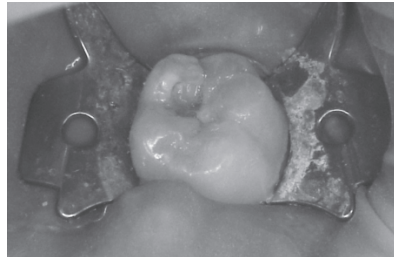

picture 17

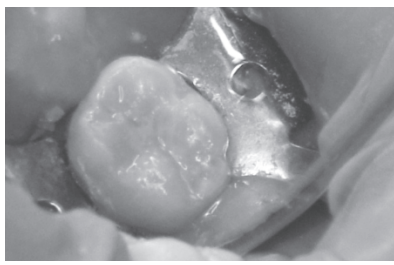

picture 19

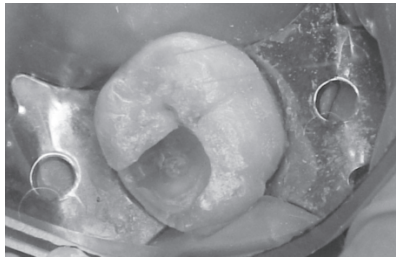

picture 18 


\section{Case report 6}

A 35-year-old male with a non-carious lesion on the cervical area of his upper central incisors was treated with an Er:YAG laser (LightWalker, Fotona, SLO) to prepare the cavities and to condition the enamel. The entire intervention was performed without anaesthetic. Parameters: $150 \mathrm{~mJ}, 10 \mathrm{~Hz}$, SSP, non-contact handpiece (0.9 mm spot).

\section{(pictures 20-21-22-23)}

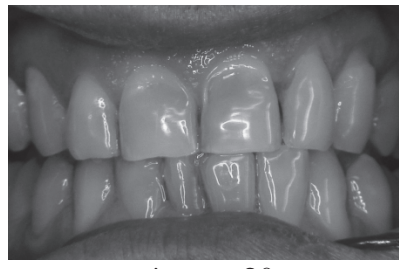

picture 20

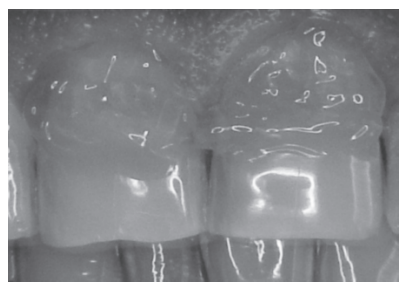

picture 22

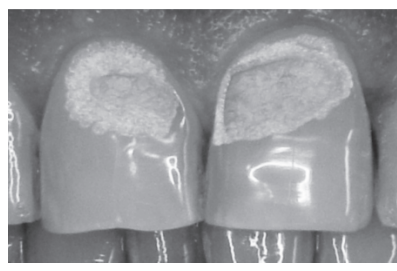

picture 21

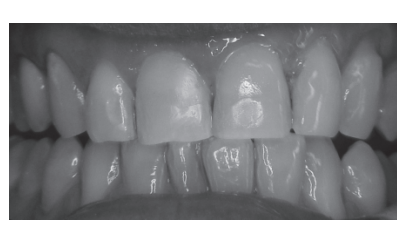

picture 23

\section{Discussion}

Laser technology was introduced in dentistry by Goldman in $1967^{19)}$ and, since that time, a major effort has been made by clinicians, researchers and companies to improve the results of clinical treatments. The introduction of Er:YAG in 1990 allowed for the treatment of hard tissues, and this development greatly contributed to the diffusion of this technology among dentists.

In recent years, significant progress has been made by companies to develop devices that are smaller, cheaper and more efficient. Moreover, new types of applications have been added to the traditional range, such as Er:YAG enamel conditioning for bracket bonding in orthodontics, and in prosthetics for enhancing the adhesion of metal-free bridges 20-21)

The possibility to have a wider range of performance parameters, lower pulse durations, and smaller handpieces with a large number of different tips have made this technique easier to use for the operator, while at the same time providing better results in term of quality. Moreover, the point of view of the patients, analyzed by means of questionnaires, has shown great satisfaction, particularly in comparison to conventional treatments, and a clear wish to continue to be treated by Er:YAG laser due to the reduced pain and greater comfort, both during and after the intervention, compared to traditional techniques. ${ }^{22)}$

\section{Conclusion}

The Er:YAG laser may be utilized in adhesive conservative dentistry as an alternative to the use of conventional instruments, such the turbine and micro-motor, and also in association with orthophosphoric acid, with several advantages such as better bond strength and reduced microleakage, as well as lower discomfort and higher patient satisfaction.

\section{References}

1: Buonocore MG. A simple method of increasing the adhesion of acrylic filling materials to enamel surface. J Dent Res;34: 849- 853, 1995.

2: Tyas MJ, Burrow MF. Adhesive restorative materials: a review. Aust Dent J;3:112-21, 2004.

3: Hibst R, Keller U. Experimental studies of the application of the Er:YAG laser on dental hard substances: I. Measurement of the ablation rate. Laser Surg Med. 9:338, 1989.

4: Keller U, Hibst R. Experimental studies of the application of the Er:YAG laser on dental hard substances: II. Light microscopic and SEM investigations. Lasers Surg Med;9:345-51, 1989.

5: Dostálová T, Jelínková H, Krejsa O, Hamal K, Kubelka J, Procházka S, Himmlová L. Dentin and pulp response to Erbium:YAG laser ablation: a preliminary evaluation of human teeth. J Clin Laser Med Surg;15:117-21, 1997.

6: Pelagalli J, Gimbel CB, Hansen RT, Swett A, Winn DW. Investigational study of the use of Er:YAG laser versus dental drill for caries removal and cavity preparation--phase I. J Clin Laser Med Surg;15:109-15, 1997.

7: Takeda FH, Harashima T, Kimura Y, Matsumoto K. Comparative study about the removal of smear layer by three types of laser devices. J Clin Laser 
Med Surg;16:117-22, 1998.

8: Glockner K, Rumpler J, Ebeleseder K, Städtler P. Intrapulpal temperature during preparation with the Er:YAG laser compared to the conventional burr: an in vitro study.

J Clin Laser Med Surg;16:153-7, 1998.

9: Rizoiu I, Kohanghadosh F, Kimmel AI, Eversole LR. Pulpal thermal responses to an erbium,chromium: YSGG pulsed laser hydrokinetic system. Oral Surg Oral Med Oral Pathol Oral Radiol Endod. ;86:220-3, 1998.

10: Ando Y, Aoki A, Watanabe H, Ishikawa I. Bactericidal effect of erbium YAG laser on periodontopathic bacteria. Lasers Surg Med.;19:190200, 1996.

11: Kornblit R, Trapani D, Bossù M, Muller-Bolla M, Rocca JP, Polimeni A. The use of Erbium:YAG laser for caries removal in paediatric patients following minimally Invasive Dentistry concepts. Eur J Paediatr Dent;9:81-7, 2008.

12: Ceballos L, Toledano M, Osorio R, Tay FR, Marshall GW. Bonding to Er:YAG laser treated dentin. J Dent Res,; 81:119, 2002.

13: Black GV. Operative Dentistry. Medico-Dental Publishing Company, Chicago, 1917.

14: Fornaini C. "Treatment Amelogenesis Imperfecta with the Er:YAG laser". LAHA clinical Bulletin, 38/11 (2011).

15: Fornaini C. Lasers in the treatment of traumatically fractured frontal teeth. International Magazine of Laser Dentistry, 4-2012.

16: Correa-Afonso AM, Pécora JD, Palma-Dibb RG. Influence of pulse repetition rate on temperature rise and working time during composite filling removal with the Er:YAG laser. Photomed Laser Surg. 2008 Jun;26(3):221-5.

17: Matsumoto K, Hossain M, Hossain MM, Kawano H, Kimura Y. Clinical assessment of Er,Cr:YSGG laser application for cavity preparation. J Clin Laser Med Surg. 2002 Feb;20(1):17-21.

18: Jacboson B, Berger J, Kravitz R and Patel P. Laser pediatric crowns performed without anesthesia: a contemporary technique. J Clin Pediatr Dent, vol. 28 (1) 2003 Fall.

:19: Goldman L: Dental applications of the laser. In Goldman L: "Biomedical aspects of the laser: the introduction of laser applications into biology and medicine." New York, 1967, Springer-Verlag.

20: Fornaini C. Laser and orthodontics. 13th Congress of World Federation for Laser in Dentistry. Barcelona, April 2012.

21: Fornaini C. Use of Er:YAG laser for effective adhesion in prosthetics. LAHA Clinical Bulletin, 5/12 (2012).

22: Fornaini C, Riceputi D, Lupi-Pegurier L, Rocca JP. Patient responses to Er:YAG laser when used for conservative dentistry. Lasers Med Sci. 2012 Nov;27(6):1143-9.

The contents of this article were originally presented as an oral paper at 14th Congress of the Asian Pacific Association for Laser Medicine \& Surgery on November 24th, 2012 in Taipei, Taiwan. 